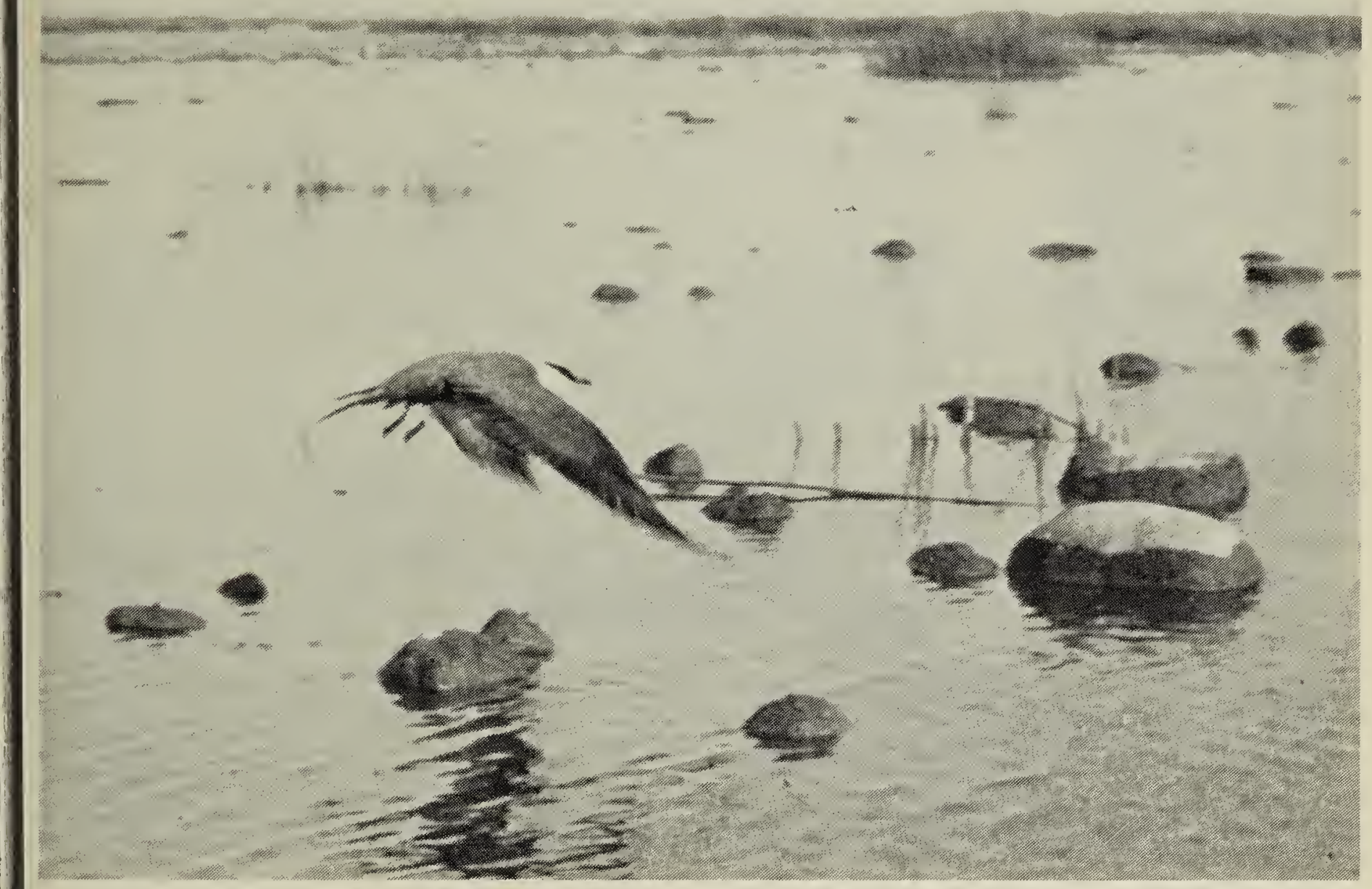

\title{
LONG-TAILED JAEGER PREYS ON LESSER YELLOWLEGS
}

DICK DEKKER, 3819 - 112a Street, Edmonton, Alberta, T6J 1 K4.

On 11 September 1977 I observed a Long-tailed Jaeger resting on a stone along the north shore of Beaverhill Lake, some $60 \mathrm{~km}$ east of Edmonton. When the jaeger flew, it flushed several waders and twice chased a lesser Yellowlegs that narrowly escaped by dropping into the water. Some distance away, the jaeger landed on the rock-strewn shore. As the low afternoon sun was behind it, I walked up to get the light at my back for a better look. Before I got there, the alarm reactions of yellowlegs and other waders prompted me to scan the shore through binoculars. I discovered the jaeger not far away, sitting in shallow water, flapping its wings for balance and pecking at something under it. At that moment, a violent squall sprang up, sending waves crashing onto the shore. The jaeger rose and flew against the wind to rest on the lake. I left to take shelter in the car, returning after the storm had abated, some 30 minutes later. 


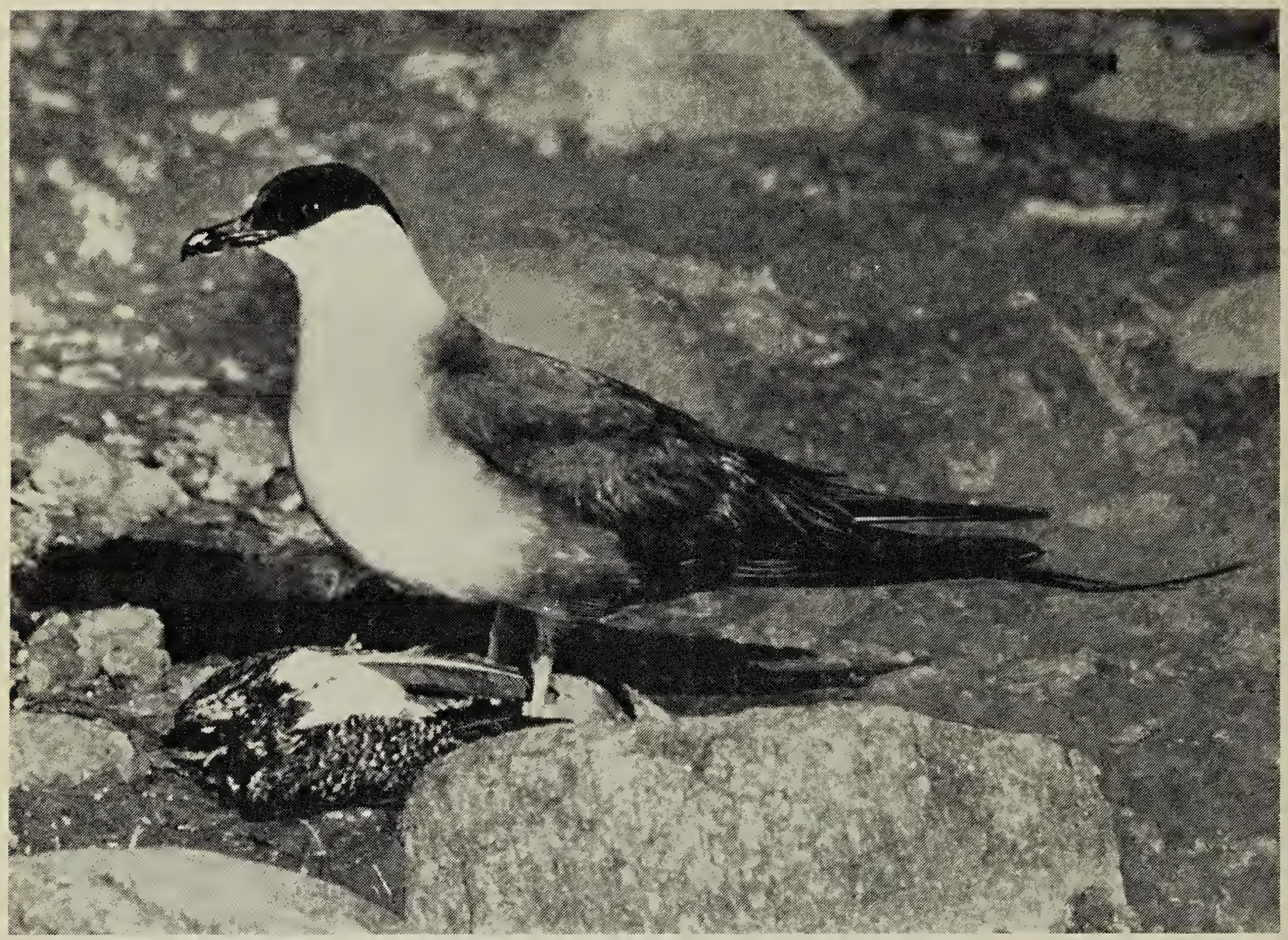

Again alerted by the alarm calls of fleeing waders, I scanned the area and once more found the jaeger sitting in shallow water, flapping its wings and occasionally pecking at something underneath it. I walked up slowly, but the jaeger left long before I got there. While I was searching for the exact spot where it had been, the bird suddenly returned and settled close-by. It began hacking away at what I found to be a freshly-killed Lesser Yellowlegs. Part of the neck and breast had been eaten; the skull was plucked and bare.

Presently, I found the jaeger along the shore where it had been pecking just prior to the storm. Again, it was feeding on a Lesser Yellowlegs.

The next day the jaeger was flushing waders in the same area. It moved in and out of view among reed beds. Eventually, I found it sitting on an ex- panse of mud, eating its third Lesser Yellowlegs, that it had no doubt just captured and killed. The bird was not shy at all and allowed me to approach to about five metres.

It was my first sighting of the Longtailed Jaeger at Beaverhill Lake, where I have recorded well over 100 unidentified and Parasitic Jaegers over the past 15 years. My records for the years 1964 to 1967 were published in the Blue Jay of March 1968, Vol. 26:16-17.

Ed. note: Remains of dowitchers, Bar-tailed Godwits and smaller shorebirds were found in the pellets of Long-tailed Jaegers in Alaska but there was no indication as to whether they were taken alive or as carrion (Maher, W.J. 1974. Ecology of Pomarine, Parasitic and Long-tailed Jaegers in northern Alaska. Pac. Coast Avifauna 37. 148 pp.). 